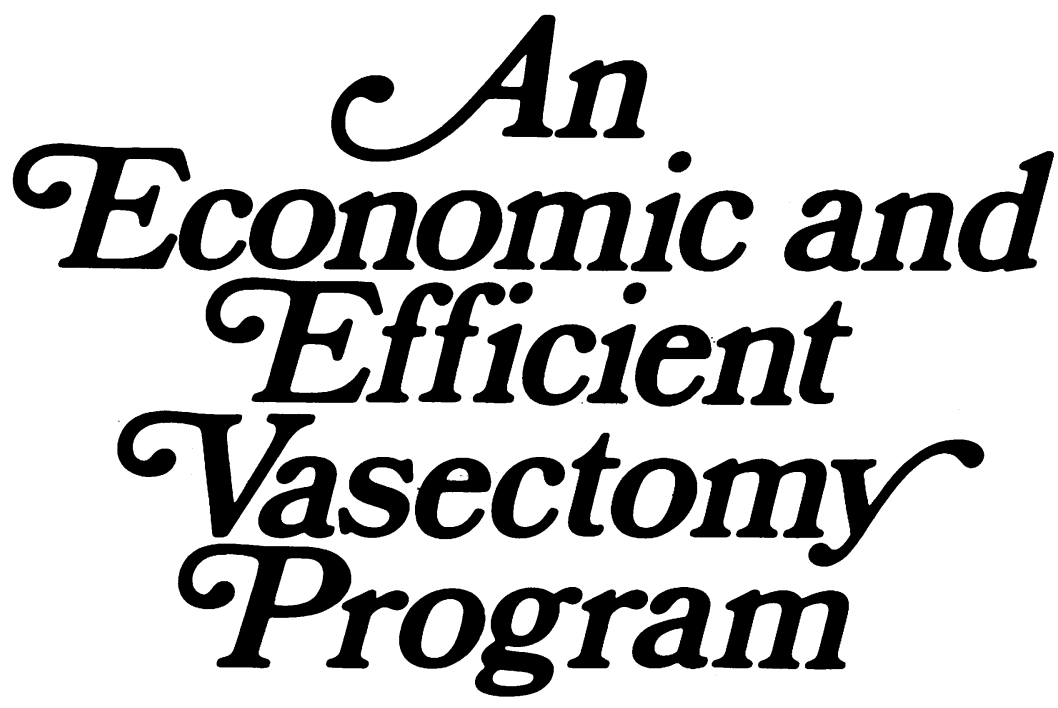

PHILIP M. SAVAGE, Jr., M.D.

Dr. Savage is project director for maternal health and family planning in the San Bernardino County Health Department. Tearsheet requests to Philip $M$. Savage, Jr., M.D., San Bernardino County Health Department, 351 Mt. View Avenue, San Bernardino, Calif. 92401.

The staff of the family planning division of the San Bernardino County (Calif.) Health Department became overwhelmingly convinced that many of their female clients needed sterilization to solve their birth control problems. Since tubal ligations were financially out of reach of most of these women, we explored the possibility of instituting male vasectomies, and by July 1970, a slow start had been made. For this effort, the health department fortunately had available a semiretired surgeon under part-time contract. By devoting a few hours of his time weekly to this activity in the beginning and, finally, 8 hours per week, this surgeon was able to work up to a be informed of the possibility of complications but be reassured that they are rare. The complications consist mainly of minor hematomas, which are of no serious consequence although they prolong the disability; infection can also occur. The man needs to be assured that a sterile technique is used, as in any other surgery.

3. The couple must be made to understand thoroughly and to appreciate the probability that the operation will be irreversible. The couple has no crystal ball to look into the future. The husband and wife must realize that they are making a mature decision with which they will have to live should a child or the wife die or some other unforeseeable event occur. They must understand that the reanastomosis of the vas deferens is only 40 to 60 percent successful so that they may be placing themselves in a position in which the husband's fertility cannot be regained. Also, should the woman become pregnant while her husband is sterile, her marriage might well be threatened.

4. The man must be informed as to how much pain to anticipate. This information should be presented on an honest and factual experience-related basis.

When the interviewer is convinced that both marital partners are thoroughly informed about the vasectomy program and understand all phases of it, they are required to sign a legal consent sheet, which was worded by the legal counsel for the county health department.

\section{Surgical Success}

We do not do pathological studies of a section of the vas deferens because of the additional expense but depend entirely on adequate microscopic 


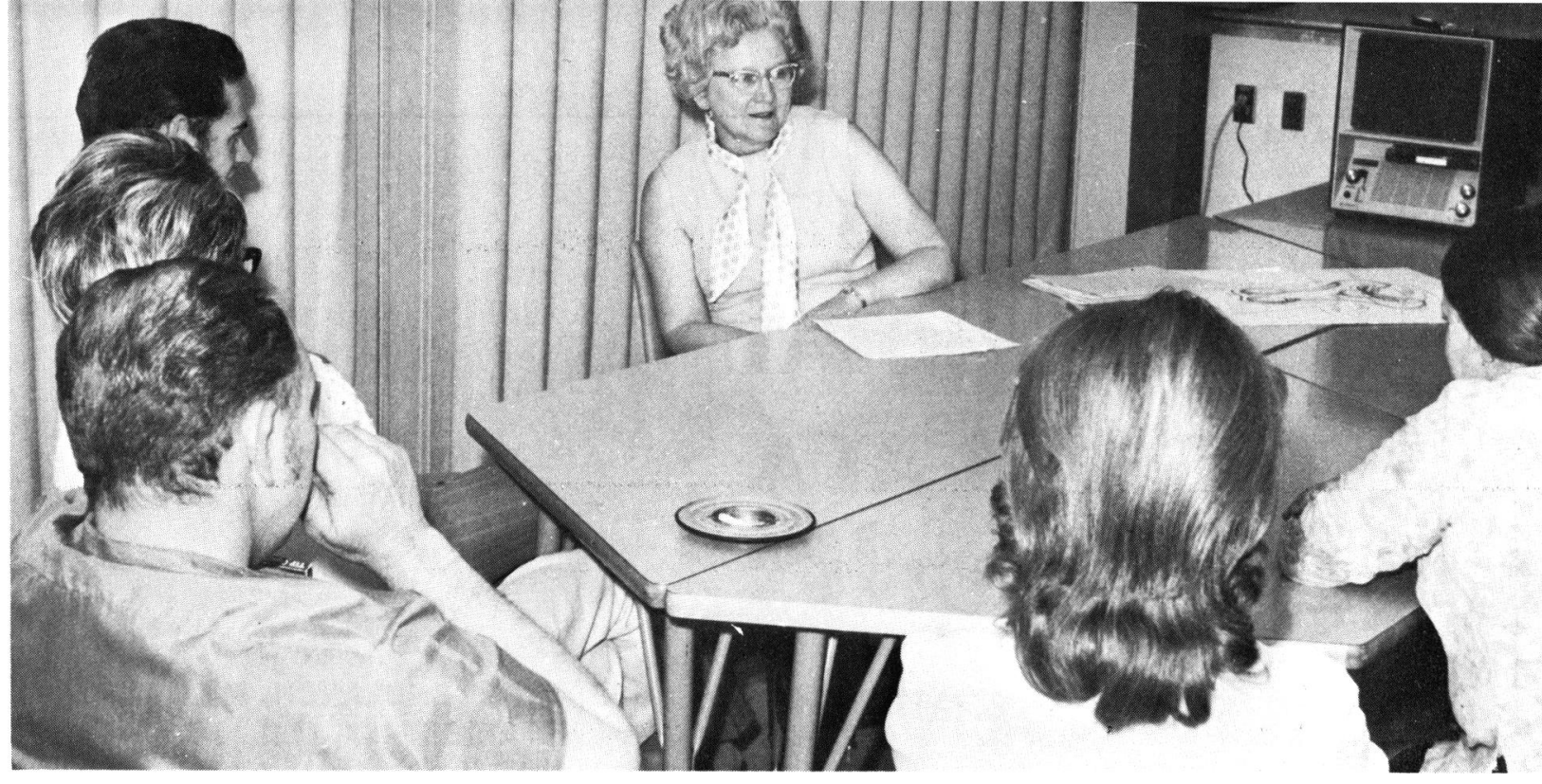

Public health nurse counselor Margaret Scott, San Bernardino County (Calif.) Health

Department, holding a consultation with husbands and wives about vasectomies.

examinations of semen specimens for proof of our results. Our local surgeon, who has been doing vasectomies for sterilization since 1936, has performed thousands of these operations and has never known of a recurrence of function in any patient. Since all of these vasectomies were done in the same community, it is reasonable to assume that he would have learned of any failures. The only charge of failure he ever faced eventually ended in a demonstration that the errant sperm came from another source than his own patient.

Our surgeon knows of no psychologically damaging results from the procedure but believes that this demonstrated outcome is closely related to the care we take in consultations.

\section{Economy of Operation}

The vasectomy service grew so rapidly that in March 1971 a second clinic was instituted in Ontario, 30 miles west of San Bernadino. This second clinic best demonstrates the economy of our program. There consultations are conducted by a well-informed and mature public health nurse. Competent surgeons have been contracted to work 2 hours per week at $\$ 40$ per hour. Each is able to complete four vasectomies in the 2 hours.

The valuable time of the physicians is used directly in surgery since a medic, discharged from military service, is hired at $\$ 2.45$ per hour to prepare each patient, to finish shaving him if necessary, to drape him, and to act as a circulating nurse. This medic also places the postoperative dressings. Our expenses are thus limited to the fees for the surgeons of $\$ 20$ per vasectomy, the approximately $\$ 10$ paid the medic, and the 3 or 4 hours of public health nursing time.

We refer all patients who are able to pay for a vasectomy to competent, interested surgeons for private care. Local surgeons, however, charge privately $\$ 125$ per vasectomy and require cash for this operation.

Our criteria for a vasectomy are a little more lenient than those of some of the private phy- sicians. We require that the man be at least 25 years old, the children must number two or more, the couple must have had trouble with ordinary birth control methods, and they must show financial need. A very few exceptions are made on occasion in respect to one or more of these criteria.

\section{Results to Date}

As of May 31, 1971, the San Bernardino clinic had completed 265 vasectomies and the Ontario clinic, 40. Of the 305 vasectomies, there was only one minor hematoma of mild significance and, in two patients, a low-grade temperature, which in each instance returned rapidly to normal after one injection of penicillin. There have been no other complications of any sort.

Vasectomy was first authorized for Federal funding by the Family Planning Services and Population Research Act of 1970, which was signed into law by President Nixon on December 26, 1970. The Congress has not yet, however, appropriated funds to activate the program. 